\title{
Erratum to: Invasibility of reservoirs in the Paraná Basin, Brazil, to Cichla kelberi Kullander and Ferreira, 2006
}

\author{
Luis A. Espínola $\cdot$ Carolina V. Minte-Vera • \\ Horácio F. Júlio Jr
}

Published online: 26 November 2009

(C) Springer Science+Business Media B.V. 2009

\section{Erratum to: Biol Invasions \\ DOI 10.1007/s10530-009-9598-x}

In the original publication under subheading "Data analysis" of the section Materials and methods, the fourth paragraph "According to Burnham and Anderson (1998), when the ratio is $\frac{n}{k}<40$, the AIC needs adjustment. Thus, the $\mathrm{AIC}_{\mathrm{c}}$ was calculated as:

$$
\mathrm{AIC}_{c}=\mathrm{AIC}+\frac{2 k(k+1)}{n-K-1}
$$

where $n$ indicates the number of observations and $K$ is the number of parameters in the model" is incorrect.

The correct version is given below.

According to Burnham and Anderson (1998), when the ratio is $\frac{n}{K}<40$, the AIC needs adjustment. Thus, the $\mathrm{AIC}_{\mathrm{c}}$ was calculated as:

The online version of the original article can be found under doi:10.1007/s10530-009-9598-x.

\section{A. Espínola ( $\square)$}

Núcleo de Pesquisas em Limnologia, Ictiologia e Aqüicultura, Universidade Estadual de Maringá, Avenida Colombo, 5790, 87020-900 Maringá, Paraná, Brazil

e-mail: laespn@gmail.com

C. V. Minte-Vera · H. F. Júlio Jr

Núcleo de Pesquisas em Limnologia, Ictiologia e Aqüicultura, DBI, Universidade Estadual de Maringá, Avenida Colombo, 5790, 87020-900 Maringá, Paraná, Brazil
$\mathrm{AIC}_{c}=\mathrm{AIC}+\frac{2 K(K+1)}{n-K-1}$

where $n$ indicates the number of observations and $K$ is the number of parameters in the model.

In the sixth paragraph first line "Because the likelihood of the model decreases with the increase of $\Delta_{i}$, the model with $4 \geq \Delta_{i} \geq 7$ has weak empirical support and should be less considered, and the model with a $\Delta_{i} \geq 10$ can be omitted because it has no strong empirical support (Burnham and Anderson 1998)" is incorrect.

The correct version is given below.

Because the likelihood of the model decreases with the increase of $\Delta_{i}$, the model with $4 \leq \Delta_{i} \leq 7$ has weak empirical support and should be less considered, and the model with a $\Delta_{i} \geq 10$ can be omitted because it has no strong empirical support (Burnham and Anderson 1998). 